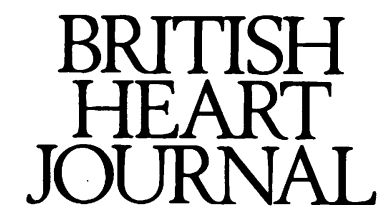

\title{
Editorial
}

\section{The angiotensin converting enzyme gene in cardiovascular disease}

In every individual there are two copies of each gene (one of paternal and the other of maternal origin). The gene structure is of sequences of the nucleic acid bases adenine, guanine, cytosine, and thymine. The numbers of these base pairs in any single gene may run into thousands. Determination of the genetic code-that is, the sequence of these bases in a gene-is now commonplace. Substitutions of a base with another base either in one gene copy (heterozygous) or both (homozygous) are known as point mutations. If they lead to the production of an abnormal protein, clinical sequelae may occur-for example, sickle cell disease. Insertion of an extra length of bases or deletion of a segment of the gene can also lead to an altered product and clinical sequelae.

It is, however, now clear that many changes in the base sequences have no apparent sequelae. Thus there are alternative forms of the gene with some changes in the base sequences but no apparent effect on the subject. The advent of gene sequencing on a large scale has shown the existence of numerous polymorphisms of many genes. Epidemiological studies have shown that different polymorphisms can confer different risks for developing diseases. The increase or decrease in risk may be minor and may be detected only by large population studies. For many polymorphisms how this effect is mediated is unknown and one of the greatest current challenges for molecular cardiology is to understand the mechanism.

The concept of an association between a gene encoding a component of the renin angiotensin system and a cardiac disease phenotype is particularly attractive in view of the accumulating evidence that ACE inhibition reduces morbidity and mortality from left ventricular dysfunction. ${ }^{1}$ When we consider such studies it is important to remember that an association between different variants of a gene and a disorder does not necessarily indicate an aetiological role. In association studies where the genotypes of unrelated cases and controls are contrasted these markers may be acting as a beacon indicating that there is a causative mutation somewhere within a $10000-100000$ base pair range.

Recently an intriguing series of genetic associations with cardiovascular disease have been reported for an insertion/deletion polymorphism, located within a noncoding region (intron 16) of the angiotensin converting enzyme gene (ACE). The polymorphism relies upon the presence (insertion) or absence (deletion) of a 287 base pair fragment, which can be amplified from genomic DNA using the polymerase chain reaction and genotyped after gel electrophoresis. ${ }^{2}$ A further stimulus to study has been the observation of a major effect of the ACE gene upon plasma ACE activity with enzyme activity being highest in those white Europeans who are homozygous for the deletion allele (DD genotype) of this insertion/deletion polymorphism. ${ }^{2}$

Perhaps the greatest incentive to study this polymorphism has been the report by Cambien et al that the deletion variant (DD genotype) associates with myocardial infarction, particularly among those at apparently low risk of this complication. ${ }^{3}$ Though this is an interesting study we must be careful not to extrapolate to a whole population observations in a retrospective, cross sectional study on survivors of myocardial infarction. By definition because $40 \%$ of those who have a myocardial infarction die in the immediate post-infarct period they were not available for genotyping in this study. Therefore the claim that the ACE gene operates an independent risk factor for infarction is diluted. Furthermore, the same polymorphism has also been associated with longevity, which raises the possibility that the DD genotype might be a marker for survival rather than a deleterious allele. ${ }^{4}$

Cambien et al recognised this problem and have developed circumstantial evidence for their risk factor hypothesis by demonstrating association of the DD genotype with a family history of death from infarction and also in a postmortem study. ${ }^{56}$ Interestingly, a study on 1226 men from the Caerphilly Heart Study has reported association of the DD genotype with coronary artery disease (CAD) in those at apparently low risk as defined by classic risk factors. This potentially widens the phenotypic relation beyond infarction in an homogenous male population, although the study emphasises that any influence of this polymorphism is likely to be quantitatively small. ${ }^{7}$

The mechanisms by which ACE might influence coronary artery disease include hypertension, cardiovascular remodelling, and atherogenesis. Genetic influence upon ACE activity may alter not only the renin-angiotensin system but also the kalikrein-kinin system or the balance between them.

Several studies have not shown a linkage or association of the ACE gene with hypertension. ${ }^{89}$ The problems with these negative studies is that with one exception they make no statement of the power they offer to rule out a remote contribution of this locus to hypertension. ${ }^{9}$ For a study to demonstrate a $12 \%$ difference in allelic frequency of the ACE I/D polymorphism (such as seen between myocardial infarction cases and controls in the study by Cambien $e t a l$ ) would require 250 infarcts $v 250$ controls to achieve a significant difference at the $5 \%$ level with $80 \%$ power. Despite this caveat, however, the 
strongest association of the DD genotype with coronary artery disease in the Caerphilly Heart Study was at normal blood pressures. ${ }^{7}$

Because hypertension seems an unlikely mechanism by which this gene product may influence CAD the possibility of an effect of ACE on atheroma must be considered. There is certainly evidence from animal models that ACE inhibitors reduce atheroma, but the precise mechanism is uncertain. ${ }^{10}$ There has been at least one negative study that has examined the relation of the I/D polymorphism to the severity of angiographically defined CAD. ${ }^{11}$ However, two small studies have now reported an association of DD genotype with restenosis after percutaneous transluminal angioplasty. ${ }^{12}{ }^{13}$ Concern has been expressed about the rigour of visual assessment of angiograms in at least one of these pilot studies that suggest an influence of the ACE gene on plaque remodelling, ${ }^{14}$ and lately a study, by Samani et al, of patients who had elective percutaneous transluminal coronary angioplasty found that the I/D polymorphism did not influence the extent of restenosis. ${ }^{15}$

Support for cardiac remodelling as a mechanism for the genetic influence of the ACE gene has emerged from studies of left ventricular hypertrophy and cardiomyopathies. ${ }^{16-18}$ In the context of CAD it is interesting that the association of DD genotype with left ventricular hypertrophy was seen particularly in normotensive men and was independent of confounding variables; although, curiously, there was no association with left ventricular hypertrophy in females. ${ }^{16}$ These observations have recently been extended in a Japanese population study which showed an independent association between the ACE genotype and left ventricular hypertrophy defined by echocardiography and on voltage criteria. ${ }^{19}$ However, this study may be influenced by some selection bias because cases were recruited from a hospital based cardiovascular disease clinic and will need evaluation in other populations. ${ }^{19}$

It has become fashionable to study the ACE I/D polymorphism but the observations will need careful refinement and extension to define the genuine associations and mechanisms. It must be remembered that there are negative studies on this polymorphism in CAD and myocardial infarction including a large prospective study based on the Physicians' Health Study. ${ }^{2021}$ The latter study of US physicians, although large, will not incorporate all social strata and may not represent the relation of ACE genotype to $\mathrm{CAD}$ in the wider population. ${ }^{21}$ Because it is increasingly difficult to publish negative genetic studies a real possibility of publication bias arises. Accordingly, when considering studies on any gene it will be important to look for confounding variables. These include highly selected patient groups from tertiary referral centres, ethnic heterogeneity, poor definition of the disease phenotype or control groups, and statements of power in negative studies.

A further potential difficulty is highlighted by the recent proposal of a "synergistic interaction" between a variant of the angiotensin type 1 receptor (AT1R) gene and the DD genotype in myocardial infarction. ${ }^{22}$ Although the study population is large there was no independent relation between the AT1R gene variant and myocardial infarction. Only after substratification that vastly reduced the population size did any putative interaction with the ACE genotype emerge-therefore this observation will need to be treated with great caution until it is confirmed in other studies.
Now that powerful molecular techniques permit screening the genome for genes causing cardiovascular disease we need to keep a firm grip on the physiology of these disorders if we really want to explore the relation of genotype and phenotype. Well designed, prospective studies may resolve some of the questions emerging from published observations. In the interim it is important to remain cautious, and perhaps optimistic about the ACE genotype and cardiovascular disease. Certainly no large prospective or cross sectional studies of a multifactorial disease should be designed without considering the genetic components.

Department of Clinical Pharmacology,

MARK CAULFIELD

St Bartholomew's Hospital,

London EC1A $7 B E$

Department of Endocrinology,

St Bartholomew's Hospital,

London EC1A $7 B E$

JOHN NEWELL-PRICE

1 The SOLVD investigators. Effect of enalapril on survival in patients with reduced ejection fractions and congestive heart failure. $N \mathrm{Engl} f \mathrm{Med}$ 1991;325:293-302.

2 Rigat B, Hubert C, Ahlenc-Gelas F, Cambien F, Corvol P, Soubrier F. An insertion/deletion polymorphism in the angiotensin 1-converting enzyme gene accounting for half the variance of serum enzyme levels. $\mathcal{f}$ Clin Invest 1990;86:1343-6.

3 Cambien F, Poirier O, Lecerf L, et al. Deletion polymorphism in the gene for angiotensin-converting enzyme is a potent risk factor for myocardial infarction. Nature 1992;359:641-4.

4 Shachter F, Faure-Delanef L, Guenot F, et al. Genetic associations with human longevity at the APOE and ACE loci. Nature Genetics 1994;6:29-32.

5 Tiret L, Kee F, Poirer O, et al. Deletion polymorphism in the angiotensinconverting enzyme gene associated with parental history of myocardial infarction. Lancet 1993;341:991-2.

6 Evans AE, Poirer O, Kee F, et al. Distribution of the angiotensin-converting enzyme gene polymorphism in subjects who die from coronary artery disease. $Q \mathcal{F}$ Med 1994;87:211-4

7 Mattu RK, Needham EWA, Galton DJ, Frangos E, Clark AJL, Caulfield $M$. A DNA variant at the angiotensin-converting enzyme gene locus associates with coronary artery disease in the Caerphilly Heart Study. Circulation 1995;91:270-4.

8 Jeunemaitre X, Lifton RP, Hunt SC, Williams RR, Lalouel J-M. Absence of linkage between the angiotensin converting enzyme locus and human essential hypertension. Nature Genetics 1992;1:72-5.

9 Harrap SB, Davidson R, Connor M, Soubrier F, Corvol P, et al. The angiotensin 1-converting enzyme gene and predisposition to high blood pressure. Hypertension 1993;21:455-60.

10 Shuh JR, Blehm DJ, Frierdich GE, McMahon EG, Blaine EH. Differential effects of renin-angiotensin system blockade on atherogene-
sis in cholesterol-fed rabbits. F Clin Invest 1993;91:1453-8.

11 Ludwig EH, Cornell PS, Anderson JL, Marshall HW, Lalouel J-M, Ward RH. The ACE insertion/deletion polymorphism is independently associated with myocardial infarction and body mass index but not with stenosis [abstr]. Circulation 1993;88:1953.

12 Ohishi M, Fujii K, Minamino T, Higaki J, Kamitani A, Rakugi H, et al. A potent genetic risk factor for restenosis. Nature Genetics 1993;5:324-5.

13 Beohar N, Prather A, Qun-Tao Yu, Gerardo M, Villareal-Levy, Raizner $\mathrm{AE}$, et al. Angiotensin converting enzyme genotype $\mathrm{DD}$ is a potent risk factor for coronary artery disease and restenosis post percutaneous angioplasty [abstr]. Circulation 1994;90:I-145, 773.

14 Kaski J. Are polymorphisms in the ACE gene a potent genetic risk factor for restenosis? Br Heart $\mathcal{F} 1994 ; 72: 101$.

15 Samani NJ, Martin DS, Brack M, Cullen J, Chauhan A, Lodwick D, et al. Insertion/deletion polymorphism in the angiotensin-converting enzyme gene and risk of restenosis after coronary angioplasty. Lancet 1995; 345:1013-6.

16 Schunkert H, Hense H-W, Holmer S, et al. Association between a deletion polymorphism of the angiotensin-converting-enzyme gene and left ventricular hypertrophy. $N$ Engl f Med 1994;330:1634-8.

17 Marian AJ, Quntao Y, Workman R, Greve R, Roberts R. Angiotensinconverting enzyme in hypertrophic cardiomyopathy and sudden cardiac death. Lancet 1993;342:1085-6.

18 Raynolds MV, Bristow MR, Bush EW, et al. Angiotensin-converting enzyme DD genotype in patients with ischaemic or dilated cardiomyopathy. Lancet 1993;342:1073-5.

19 Iwai N, Ohmichi N, Nakamura Y, Kinoshita M. DD genotype of the angiotensin-converting enzyme gene is a risk factor for left ventricular hypertrophy. Circulation 1994;90:2622-8.

20 Bohn M, Berge KE, Bakken A, Erikssen J, Berg K. Insertion/deletion polymorphism at the locus for angiotensin I-converting enzyme and myocardial infarction. Clin Genet 1993;44:292-7.

21 Lindpaintner $\mathrm{K}$, Pfeffer MA, Kreutz $R$, et al. A prospective evaluation of an angiotensin-converting-enzyme gene polymorphism and the risk for ischemic heart disease. N Engl F Med 1995;332:706-11.

22 Tiret L, Bonnardeaux A, Poirer O, et al. Synergistic effects of angiotensinconverting enzyme and angiotensin II type 1 receptor gene polymorphisms on risk of myocardial infarction. Lancet 1994;344:910-3. 